\title{
Amyloid deposition in a mouse model humanized at the transthyretin and retinol-binding protein 4 loci
}

\author{
Xiangshun $\mathrm{Li}^{1} \cdot$ Yanyi Lyu ${ }^{2} \cdot$ Jingling Shen ${ }^{2} \cdot$ Yanshuang $\mathrm{Mu}^{3} \cdot \mathrm{Lixia} \mathrm{Qiang}^{1} \cdot \mathrm{Li} \mathrm{Liu}^{2} \cdot \mathrm{Kimi} \mathrm{Araki}^{4}$.

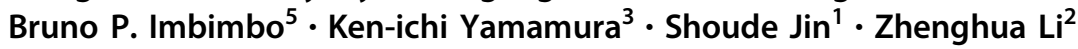

Received: 29 August 2017 / Revised: 29 November 2017 / Accepted: 2 December 2017

(c) United States \& Canadian Academy of Pathology 2018

\begin{abstract}
Familial amyloidotic polyneuropathy is an autosomal dominant disorder caused by a point mutation in the transthyretin (TTR) gene. The process of TTR amyloidogenesis begins with rate-limiting dissociation of the TTR tetramer. Thus, the TTR stabilizers, such as Tafamidis and Diflunisal, are now in clinical trials. Mouse models will be useful to testing the efficacy of these drugs. Although several mouse models have been generated, they all express mouse Rbp4. Thus, human TTR associates with mouse RBP4, resulting in different kinetic and thermodynamic stability profiles of TTR tetramers. To overcome this problem, we previously produced humanized mouse strains at both the TTR and Rbp4 loci (Ttr ${ }^{h T T R V a l 30}$, $T t r^{h T R M e t 30}$, and $\left.R b p 4^{h R B P 4}\right)$. By mating these mice, we produced double-humanized mouse strains, $T t r^{h T T R V a l 30 / h T R V a l 30}$ : $R b p 4^{h R B P 4 / h R B P 4}$ and $T t r^{h T T R V a l 30 / M e t 30}: R b p 4^{h R B P 4 / h R B P 4}$. We used conventional transgenic mouse strains on a wild-type $\left(\operatorname{Ttr}^{+/+}: \operatorname{Tg}[6.0 h T T R M e t 30]\right)$ or knockout Ttr background $\left(\operatorname{Ttr}^{-1-}: T g[6.0 h T T R M e t 30]\right)$ as reference strains. The doublehumanized mouse showed 1/25 of serum hTTR and 1/40 of serum hRBP4 levels. However, amyloid deposition was more pronounced in $T t r^{h T T R V a l 30 / M e t 30}: R b p 4^{h R B P 4 / h R B P 4}$ than in conventional transgenic mouse strains. In addition, a similar amount of amyloid deposition was also observed in $T t^{h T T R V a l 30 / h T T R V a l 30}: R b p 4^{h R B P 4 / h R B P 4}$ mice that carried the wild-type human TTR gene. Furthermore, amyloid deposition was first observed in the sciatic nerve without any additional genetic change. In all strains, anti-TTR antibody-positive deposits were found in earlier age and at higher percentage than amyloid fibril deposition. In double-humanized mice, gel filtration analysis of serum revealed that most hTTR was free of hRBP4, suggesting importance of free TTR for amyloid deposition.
\end{abstract}

Xiangshun Li and Yanyi Lyu contributed equally to this work.

Shoude Jin

jinshoude@163.com

$\triangle$ Zhenghua Li

lizhenghua@hrbmu.edu.cn

liseika@kumamoto-u.ac.jp

1 Division of Respiratory Disease, The Fourth Affiliated Hospital of Harbin Medical University, Harbin, China

2 Department of Histology and Embryology, Harbin Medical University, Harbin, China

3 Yamamura Project Laboratory, Institute of Resource Development and Analysis, Kumamoto University, Kumamoto, Japan

4 Department of Developmental Genetics, Institute of Resource Development and Analysis, Kumamoto University, Kumamoto, Japan

5 Research and Development, Chiesi Farmaceutici, Parma, Italy

\section{Introduction}

Transthyretin (TTR)-associated amyloidosis (ATTR) is an autosomal dominant disorder caused by a point mutation in the TTR gene. According to the online registry for hereditary amyloidosis mutations (http://www. amyloidosismutations.com), 138 TTR mutations are associated to human amyloidosis. TTR is a 127 -amino acid, 55-kDa protein composed of four identical, non-covalently associated subunits [1, 2]. TTR serves as a transport molecule for thyroxine (T4) and retinol-binding protein 4 (RBP4). The process of TTR amyloidogenesis involves rate-limiting dissociation of the TTR tetramer, followed by partial unfolding of monomers to yield non-fibrillar aggregates, protofibrils, and mature amyloid fibrils [3-5]. Structural studies of the TTR tetramer yielded several compounds that bind to the T4 hormone pocket of TTR, consequently stabilizing TTR and inhibiting fibril formation [6-11]. 
To gain insight into the pathogenesis of ATTR, several groups have generated transgenic mice that carry TTR genes with various mutations, such as Met30, Ser10/Met30, Pro55, or Ser84 [12-18]. Using the mouse metallothionein promoter or the human homologous TTR promoter, we produced transgenic mice in which amyloid deposition was observed in similar tissues as in human autopsy cases, except for its absence in the peripheral and autonomic nervous systems [15, 18]. Teng et al. [16] have also reported amyloid deposition in transgenic mice carrying the wild-type human TTR gene. By contrast, transgenic mouse strains with amyloidogenic Pro55 develop non-fibrillar TTR deposition, but fail to develop amyloid deposits in a 129S1/ Sv background [12]. Later, Reixach et al. [19] demonstrated that heterotetramers comprising mouse and human subunits are kinetically more stable than those of human homotetramers and are considered to be inhibitory to dissociation and subsequent amyloid formation. Sousa et al. [12] reported the presence of amyloid fibrils in Pro55 transgenic mice on a TTR-null background.

Although liver transplantation is a promising approach for preventing disease progression, its utility of liver transplantation is limited by restricted donor availability, patient eligibility, and the risk of adverse events [20-26]. Several compounds that bind to the T4 hormone pocket were shown to stabilize the TTR tetramer thereby inhibiting fibril formation. Two TTR stabilizers, such as Tafamidis and Diflunisal, are now in clinical trials, and Tafamidis was approved in the European Union in 2011. Although both drugs seem to slow disease progression, no therapy can reverse the disease course [27-30]. Thus, there is an urgent medical need for new treatments that can halt or reverse the progression of amyloidosis and that are effective across all genotypes and disease stages.

Animal models that reproduce the pathology of human TTR-mediated familial amyloidosis are required to assess the in vivo efficacy of drug candidates. We previously produced humanized mice (Ttr ${ }^{h T T R V a l 30}$ and $\operatorname{Ttr}^{h T T R M e t 30}$ ) carrying either human normal $(h V)$ or mutant $(h M) T T R$ cDNA at the mouse Ttr locus using a Cre-mediated recombination system [31]. To test the stabilizing activity of drugs in vivo, we think it is essential to mimic the physiologic condition of human serum, where human TTR binds to human RBP4. Thus, we also created a humanized mouse $\left(R b p 4^{h R B P 4}\right)$ carrying the human $R B P 4(h R)$ cDNA at the mouse Rbp4 locus using the same strategy [32-34]. We then crossed these lines to generate mice humanized mice with a normal $\left(T t r^{h T T R V 30 / h T T R V 30}: R b p 4^{h R B P 4 / h R B 4}\right.$, abbreviated as $h V / h V: h R / h R)$ or patient genotype (Ttr ${ }^{h T T R V 30 /}$ ${ }^{h T T R M 30}: R b p 4^{h R B P 4 / h R B 4}$, abbreviated as $\left.h V / h M: h R / h R\right)$. Here we examined amyloid deposition in these doublehumanized mice compared with conventional transgenic mouse strains on a wild-type $\left(\mathrm{Ttr}^{+/+}: \operatorname{Tg}[6.0\right.$ hTTRMet30], abbreviated as $+/+: T g$ ) or knockout Ttr background $\left(\mathrm{Ttr}^{-l-}: \operatorname{Tg}[6.0 h T T R M e t 30]\right.$, abbreviated as $-/-: T g$ ).

\section{Materials and methods}

\section{Conventional Transgenic Mouse Strains}

Wild-type $(+/+: T g)$ or knockout Ttr background (-/-:Tg) hemizygous mice for the 6.0hTTRMet 30 gene were used as control. These mice contained $\sim 30$ copies of the 6.0hTTRMet30 gene [35].

\section{Construction of the Targeting/Replacement Vectors and the Isolation of Targeted/Replaced ES Cells}

The construction of the targeting vector and the isolation of targeted ES cells for the mouse Ttr locus were achieved using a previously described method [31]. Briefly, a 3-kb 5' homologous region upstream of the ATG codon and a 6.7$\mathrm{kb} \mathrm{3'}$ homologous region downstream of the ATG codon were ligated into a p71neoP cassette containing lox71PGK-neo-loxP-polyA, to produce the TTR71neoPTTR construct that comprised $5^{\prime}$ Ttr homologous region-lox71PGK-neo-loxP-polyA-3' Ttr homologous region. Finally, a diphtheria toxin A (DT-A) fragment with an MC1 promoter was ligated to the $5^{\prime}$-end of TTR71neoPTTR to produce the targeting vector (Fig. 1a). The targeting vectors were introduced into TT2 ES cells [36] derived from an F1 embryo obtained from a mating between C57BL/6 and CBA mice (Charles River, Inc., Yokohama, Japan). To generate the replacement vector, we first made a cassette that contained a rabbit $\beta$-globin intron II, a $h V$ cDNA or a $h M$ cDNA, and a puromycin resistance gene with the phosphoglycerate kinase promoter (PGKpuro) flanked by two Flp recognition target (FRT) sequences. Then, the cassette flanked by lox66 and loxP sites was inserted into pSP73 (Promega, Tokyo, Japan) (Fig. 1a). The ES cell lines with the Ttr-targeted null allele were coelectroporated (BioRad Gene Pulser at $400 \mathrm{~V}$ and $125 \mu \mathrm{F}$ ) with $20 \mu \mathrm{g}$ of replacement vector plasmid and $20 \mu \mathrm{g}$ of pCAGGS-Cre plasmid [37] to produce ES clones with the replaced allele.

The construction of the targeting vector and the isolation of targeted ES cells for the mouse Rbp4 locus were achieved using a previously described method (Fig. 1b) [32, 34]. Briefly, a 2.8-kb $5^{\prime}$ homologous region upstream of the ATG codon and a 6.7-kb 3' homologous region downstream of the ATG codon were ligated into a p71neoP cassette containing lox71-PGK-neo-loxP-polyA, to produce the RBP471neoPRBP4 construct (5' Rbp4 homologous regionlox71-PGK-neo-loxP-polyA-3' Rbp4 homologous region). Finally, a diphtheria toxin A (DT-A) fragment with an MC1 promoter was ligated to the $3^{\prime}$-end of $3^{\prime} R b p 4$ homologous 
Fig. 1 Creation of targeted and replaced alleles. a Ttr locus.

Homologous recombination between the wild-type allele and the targeting vector resulted in the creation of a targeted null allele carrying the PGK-neo gene flanked by lox71 and loxP. In the second step, the targeted clones were electroporated with the replacement vector containing $h V$ or $h M$ cDNA flanked by lox 66 and loxP. Sitedirected recombination occurred between lox71/lox66 and lox $\mathrm{P} /$ lox $\mathrm{P}$, resulting in the creation of the replaced allele, $T t r^{h V}$ or $T t r^{h M}$. b Rbp4 locus.

Homologous recombination between the wild-type allele and the targeting vector yielded a targeted null allele carrying the PGK-neo gene flanked by lox 71 and $l o x P$. In the second step, targeted clones were electroporated with the replacement vector containing hRBP4 ORF flanked by loxKMR3 and loxP. Sitedirected recombination between lox71/loxKMR3 and lox $\mathrm{P} /$ lox $\mathrm{P}$ resulted in the creation of the replaced allele, $R b p 4^{h R}$

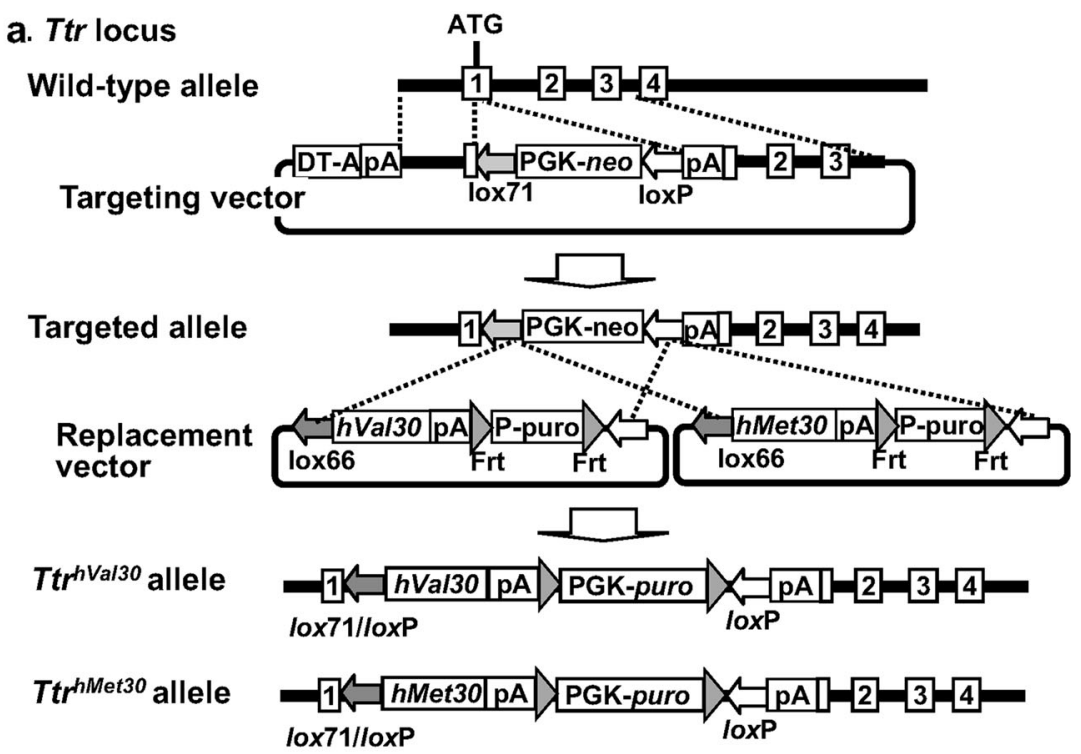

b. Rbp4 locus

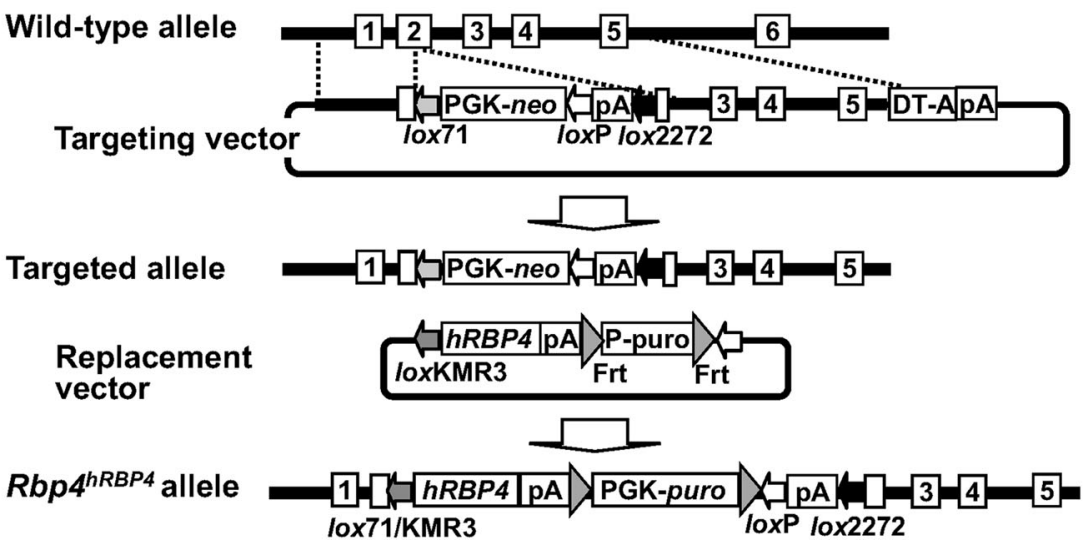

region to produce the targeting vector. The targeting vectors were introduced into TT2 ES cells [36]. To construct the replacement vector, we first made a cassette that contained a human RBP4 cDNA and a puromycin resistance gene with the PGK promoter (PGKpuro) flanked by two FRT sequences. Then, the cassette flanked by loxKMR3 and loxP sites was inserted into pSP73 (Promega, Tokyo, Japan). The ES cell lines with the Rbp4-targeted null allele were coelectroporated (Bio-Rad Gene Pulser at $400 \mathrm{~V}, 125 \mu \mathrm{F}$ ) with $20 \mu \mathrm{g}$ of replacement vector plasmid and $20 \mu \mathrm{g}$ of pCAGGS-Cre plasmid [37] to produce ES clones with the replaced allele.

\section{PCR and Southern Blot Analyses of Isolated Targeted ES Clones}

The Ttr targeted ES clones were screened and confirmed by long PCR and Southern blot analyses using genomic DNA purified by phenol, chloroform and ethanol precipitation from ES cells. In the long PCR analysis, the primers, 2-20-1S (5'- GTAAGCAATCTTAGCCAGGCTCTCC-3') and lox71-PR (5'-TATACGAACGGTATAGGTCCCTCGAC$\left.3^{\prime}\right)$, were used to detect the $5^{\prime}$ end of the targeted allele (3.0 $\mathrm{kb})$. The primers mTtr6 (5'-TGGGCTGAGTCTCTCAATTCTG-3') and neo-F (5'-AGAGGCTATTCGGCTATGAC- $3^{\prime}$ ) were used to detect the $3^{\prime}$-end of the targeted allele $(9.0 \mathrm{~kb})$. For Southern blot analysis, DNAs from ES cells was digested with BamHI or XbaI and were analyzed for the presence of the targeted allele using a neo probe. Digested DNAs was electrophoresed on a $1.2 \%$ agarose gel and blotted onto nylon membranes (Hybond-N+; Amersham, Tokyo, Japan). After the membranes were cross-linked by exposure to ultraviolet light (UV Stratalinker 1800; Stratagene, La Jolla, CA, USA), hybridization was performed using a neomycin-specific probe prepared using a DIG DNA labeling and detection kit (Roche, Tokyo, Japan). 
The Rbp4-targeted ES cell clones were confirmed by Southern blot analyses as described previously [34]. For detection of homologous recombination in the $5^{\prime}$ region, DNA from ES cells was digested with XhoI/SalI or MunI and the targeted allele was detected with a neo probe and a $5^{\prime}$ probe; for detection of homologous recombination in the $3^{\prime}$ region, AgeI/HpaI or SacII/ HpaI digestion and a neo probe and $3^{\prime}$ probe were used, respectively.

\section{PCR and Southern Blot Analyses for Genotyping of ES Clones or Mice}

Genotypes of ES cells and mice at the Ttr locus were determined by PCR analyses and confirmed by Southern blot analysis using genomic DNA from ES cells or tails according to the previously described methods [31]. Briefly, in the PCR analysis, the primers mTtr A9-s (5'-CGTAGAGCGAGTGTTCCG-3') and mTtr19 (5'CAGCTGTTGCTATAGTAATTCCC-3') were used to detect the wild-type mouse $T t r$ allele $(864 \mathrm{bp}$ ); the primers neo-R (5'-CACCATGATATTCGGCAAGC-3') and neo-F (5'-AGAGGCTATTCGGCTATGAC-3') were used to detect the targeted allele (545 bp); and the primers A9-s and SP-A (5'-CAGTGTATATCATTGTAACC-3') were used to detect the replaced allele $(783 \mathrm{bp})$. For Southern blot analysis, $10 \mu \mathrm{g}$ of DNA from mice with the targeted allele and replaced allele was digested with BamHI or XbaI and $B a m \mathrm{HI}$ or $B g l \mathrm{II}$, and was analyzed using a neo-specific or puromycin-specific probe, respectively.

Genotypes of ES cells and mice at the Rbp4 locus were determined by PCR analyses and confirmed by Southern blot analysis using genomic DNA from ES cells or tails according to previously described methods [32, 34]. Briefly, in the PCR analysis, the primers neo-R (5'-CACCATGATATTCGGCAAGC-3') and neo-F (5'AGAGGCTATTCGGCTATGAC-3') were used to detect the targeted allele (545 bp); the primers mRbp4 GSPF1 (5'-CTCGGCTCCGTCGCTCCACG-3') and mRbp4 GSPR1 (5'-CCAGAGCCCAGAGAACTGAG -3') were used to detect the wild-type mouse $R b p 4$ allele (403 bp) and the replaced allele (3421 bp). To detect homologous recombination in the $5^{\prime}$ region, DNA from ES cells was digested with XhoI/SalI or MunI and analyzed for the presence of the targeted allele using a neo and $5^{\prime}$ probes. To detect homologous recombination in the $3^{\prime}$ region, DNA from ES cells was digested with AgeI/HpaI or SacII/ $H p a \mathrm{I}$ and analyzed for the presence of the targeted allele using neo and $3^{\prime}$ probes. To detect the replaced allele genomic DNA from ES cells was digested with BamHI or $B g l \mathrm{II}$ and was used for Southern blot analysis with a puromycin-specific probe.

\section{Generation of Mouse Ttr or Rbp4 Knockout Mice and Human TTR or RBP4 Knock-in Mice}

Chimeric mice were produced by aggregation of ES cells with eight-cell embryos from ICR mice according to previously described methods [31]. Chimeric male mice were backcrossed to C57BL/6 females (Nippon Clea, Kanagawa, Japan) and mice from after the tenth generation were used in the following experiments. The experimental protocols that involved animals were approved by the Kumamoto University Ethics Committee for Animal Experiments (F25329, F27-122), and all experiments were performed in accordance with the institute's guidelines.

\section{Serum hTTR, mRBP4 and hRBP4 levels}

Commercial ELISA kits were used according to the manufacturers' instructions to determine the serum concentrations of hTTR (KA0495, Abnova, Taipei, China), mRBP4 (Mouse Retinol-Binding protein 4 ELISA Kit SimpleStep, ab202404, Abcam, Tokyo, Japan) and hRBP4 (AG-45A0035YEK-KI01, AdipoGen, San Diego, CA, USA). Elisa assay was performed when the male mice were at 3,12 , and 24 months of age.

\section{Histochemical and Immunohistochemical Analysis}

Male mice were used for histochemical and immunohistochemical analyses. Mice were killed by cervical dislocation at 12, 18, and 24 months of age. Tissues-brain, heart, kidneys, spleen, skeletal muscle, stomach, small and large intestines, and sciatic nerves-were excised, fixed in $10 \%$ neutral-buffered formalin, and embedded in paraffin. Paraffin sections were stained with hematoxylin and eosin. For histochemical demonstration of amyloid, the serial sections were stained with Congo Red according to Wright's method. To detect the emerald green birefringence emitted from the amyloid deposits, a polarized microscope was used to examine the Congo Red stained sections.

For immunohistochemical demonstration of the major components of amyloid deposits, the serial sections were immunostained by the indirect immunoperoxidase method. The primary antibodies were rabbit anti-human TTR (diluted 1:500; Sigma-Aldrich, Tokyo, Japan) or goat anti-mouse serum amyloid A (SAA) $(15 \mu \mathrm{g} / \mathrm{ml}, \mathrm{R} \& \mathrm{D}$ Systems, Tokyo, Japan) polyclonal antibodies. The primary antibodies were detected with biotinylated anti-rabbit or anti-goat secondary antibody (diluted 1:200; Vectastain ABC Kit; Vector Laboratories, Burlingame, $\mathrm{CA}$ ) and $\mathrm{DAB}$ detection kit (Ventana Medical Systems, Tucson, AZ) according to the manufacturer's instructions. To obtain negative controls, the same procedure was done without the primary antibodies. 
Fig. 2 Serum levels of hTTR and hRBP4. a Serum hTTR levels in $+/+: T g$ and $-/-: T g$ mice. b Serum hTTR levels in $h V / h V: h R / h R$ and $h V / h M: h R / h R$ mice. c Serum mRBP4 levels in $+/+: T g$ and $-/-: T g$ mice. $\mathbf{d}$ Serum hRBP4 levels in $h V / h V$ : $h R / h R$ and $h V / h M: h R / h R$ mice.

There was no significant difference in mean hTTR, mRBP4, and hRBP4 serum levels among age groups a
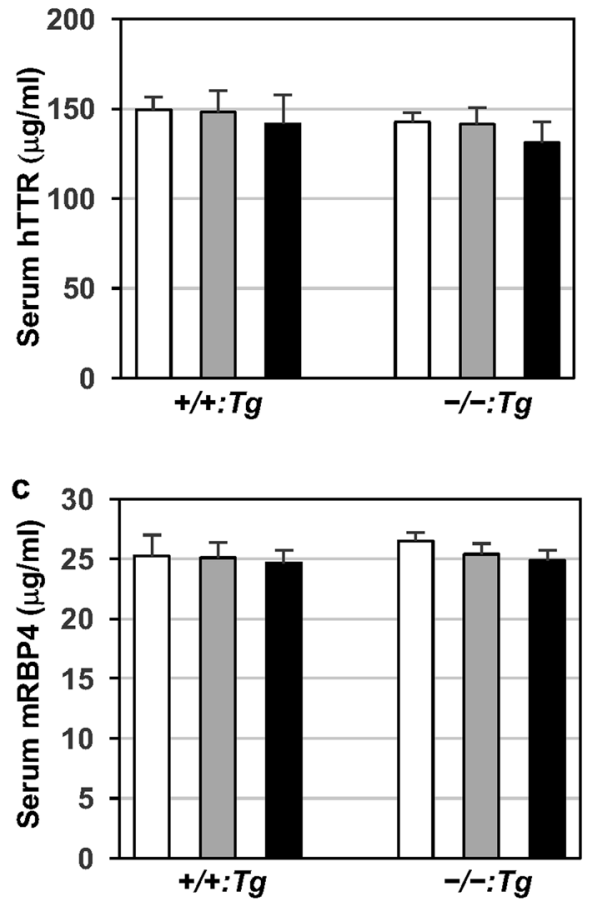

b
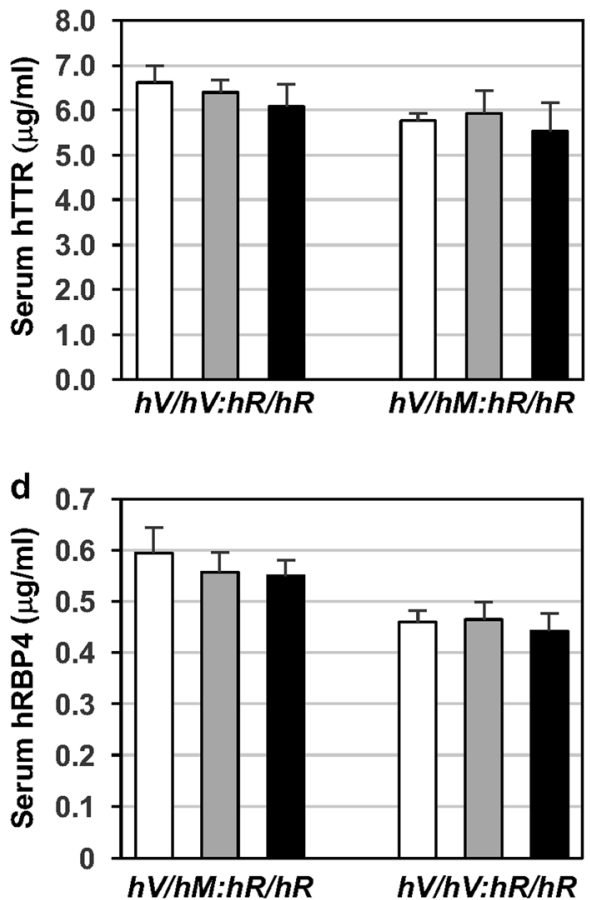

3 months of age

24 months of age

\section{Gel Filtration Chromatography to Separate RBP4-TTR Complexes}

Plasma $(0.1 \mathrm{ml})$ diluted with same volume of buffer (100nmol/L $\mathrm{Na}_{2} \mathrm{PO}_{4}-\mathrm{NaH}_{2} \mathrm{PO}_{4}, \mathrm{pH} 7.4$ ) was loaded onto a Superdex 200 Increase $10 / 300 \mathrm{GL}$ column (GE Healthcare, Tokyo, Japan) column connected to an LC8020 HPLC system (Toso, Tokyo, Japan). Protein complexes were separated by passing phosphate-buffered saline through at $0.5 \mathrm{ml} / \mathrm{min}$ for $50 \mathrm{~min}$ at room temperature. Eluted proteins were detected by their absorbance at $280 \mathrm{~nm}$ and collected in $0.5-\mathrm{ml}$ fractions for analysis by SDS-PAGE.

\section{Statistical Analysis}

Amyloid deposition was widely distributed in tissues. Thus, it is difficult to use ImageJ to quantify tissue deposition. Instead, we used simply pathological criteria to quantify tissue deposition. For example, no amyloid deposition was scored as $0 ; \pm$ (deposition limited to the walls of small vessels) as $1 ;+$ (deposition in walls of small vessels and surrounding areas) as $2 ;++$ (moderate deposition in interstitium) as 3 ; and +++ (marked deposition in interstitium and parenchyma) as 4. Mann-Whitney $U$-test was used for the statistical analysis. $P<0.05$ was considered to indicate a significant difference.

\section{Results}

\section{Establishment of ES Clones and Mouse Strains with the Targeted Null Allele or Replaced Allele}

The mouse lines carrying either $h V$ or $h M$ at the mouse $T t r$ locus have been described previously [31]. Mouse lines with $h R$ at the mouse $R b p 4$ locus (humanized Rbp4 mice) were produced in a similar way as humanized TTR mice [32]. Briefly, the replaced allele was created in two steps. First, the targeted null allele was generated by disrupting the ATG exon, which is in exon 1 in the Ttr gene (Fig. 1a) and exon 2 in the Rbp 4 gene (Fig. 1b), using a targeting vector containing a neomycin (neo) resistance gene flanked by lox71 and loxP sites. Second, the Cre-mediated site-specific introduction of $h V, h M$ or $h R$ cDNA was performed to produce the replaced allele (Fig. 1a, b).

These humanized mice were bred to produce two mouse strains: $h V / h V: h R / h R$ and $h V / h M: h R / h R$. Mice carrying the humanized allele were bred to homozygosity [33]; heterozygous and homozygous mice were born at the expected from Mendelian ratio.

In addition, we used two other transgenic strains, $+/+: T g$ [38] and $-/-: T g$ that were established by mating $+/+: T g$ with Ttr knockout mice. These mice carry the $h M$ gene harboring a 6.0-kb upstream region on the C57BL/6 background or the Ttr-null background, respectively. 


\section{Serum hTTR, mRBP4, and hRBP4 Levels}

Four mice in each strain were used for the examination of serum hTTR, mRBP4, and hRBP4 levels. In $+/+: T g$ mice, mean $( \pm$ SEM) hTTR serum levels at 3,12 , and 24 months of age were $149 \pm 7.53,148 \pm 12.17$, and $142 \pm 16.19 \mu \mathrm{g} /$ $\mathrm{ml}$, respectively (Fig. 2a, left panel). In $-/-: T g$ mice, mean $( \pm$ SEM) hTTR serum levels at 3,12 , and 24 months of age were $143 \pm 5.12, \quad 141 \pm 9.39$, and $131 \pm 11.62 \mu \mathrm{g} / \mathrm{ml}$, respectively (Fig. 2a, right panel). The corresponding values for $h V / h V: h R / h$ mice were $6.62 \pm 0.37,6.40 \pm 0.28$, and $6.06 \pm 0.49 \mu \mathrm{g} / \mathrm{ml}$, respectively (Fig. $2 \mathrm{~b}$, left panel), while in $h V / h M: h R / h R$ mice they were $5.77 \pm 0.16,5.94 \pm 0.50$, and $5.53 \pm 0.64 \mu \mathrm{g} / \mathrm{ml}$, respectively (Fig. $2 \mathrm{~b}$, right panel). In all mouse strains, there was no significant difference in mean hTTR serum levels among age groups. Although there was a trend of lower TTR levels in $h V / h M: h R / h R$ mice than in $h V / h V: h R / h R$ mice, the difference was not significant. Thus, the serum hTTR level in $h V / h V: h R / h R$ mice or $h V / h M: h R / h R$ mice was $\sim 1 / 25$ of that in $+/+: T g$ or $-/-$ : $T g$ mice.

In $+/+: T g$ mice, mean serum levels of mRBP4 at 3, 12, and 24 months of age were $25.2 \pm 1.77,25.1 \pm 1.28$, and $24.7 \pm 1.06 \mu \mathrm{g} / \mathrm{ml}$, respectively (Fig. 2c, left panel). The corresponding serum mRBP4 levels were $26.5 \pm 0.69,25.4$ \pm 0.89 , and $24.9 \pm 0.87 \mu \mathrm{g} / \mathrm{ml}$, respectively, in $-/-: T g$ mice (Fig. 2c, right panel). In $h V / h V: h R / h R$ mice, mean serum levels of hRBP4 at 3 months, 12 months and 24 months of age were $0.60 \pm 0.05,0.56 \pm 0.04$, and $0.55 \pm$ $0.03 \mu \mathrm{g} / \mathrm{ml}$, respectively (Fig. 2d, left panel). The corresponding mean serum hRBP4 in $h V / h M: h R / h R$ mice were $0.46 \pm 0.02,0.47 \pm 0.03$, and $0.44 \pm 0.03 \mu \mathrm{g} / \mathrm{ml}$, respectively (Fig. 2d, right panel). In all mouse strains, there were no significant differences in serum mouse or human RBP4 levels among age groups. As we reported previously [32], the serum level of hRBP4 in $h R / h R\left(R b p 4^{h R B P 4 / h R B P 4}\right)$ mice was $7.8 \pm 0.53 \mu \mathrm{g} / \mathrm{ml}$. Thus, these data suggested that low serum hTTR levels resulted in low RBP4 levels, probably due to a low percentage of TTR-bound hRBP4 and glomerular filtration of non-TTR-bound RBP4 into urine. Again, there was a trend of lower RBP4 in $h V / h M: h R / h R$ mice than in $h V / h V: h R / h R$ mice, but this difference was not significant.

\section{Physical Features}

As the serum TTR and RBP4 levels were considerably low, we examined the mortality rate, body weight, food consumption, and clinical chemistry to verify the effects of gene modification. Among 15 mice in each group, 4, 3, 5, and 6 mice were found dead in the $+/+: T g,-/: T g, h V / h V$ : $h R / h R$, and $h V / h M: h R / h R$ groups, respectively, before completion of the 24-month observation period. Thus, the

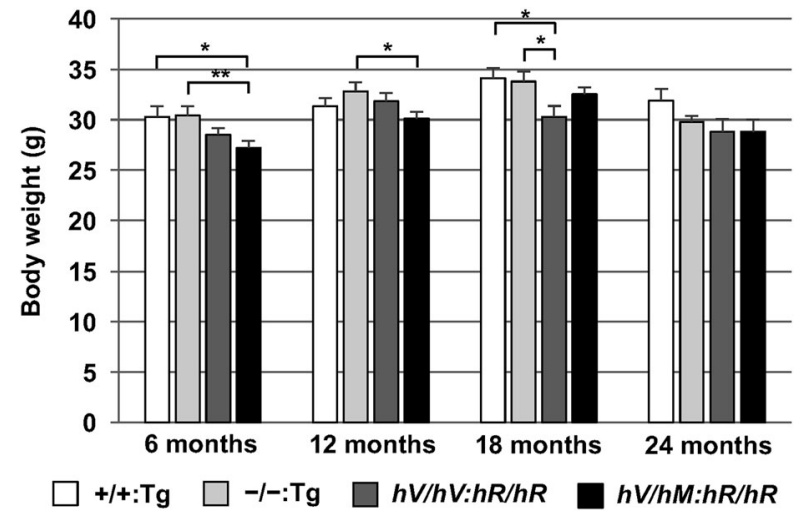

Fig. 3 Time-courses of the mean body weight gain. Although the mean body weight of $h V / h V: h R / h R$ and $h V / h M: h R / h R$ mice was slightly lower at some points, there was no difference at 24 months of age among the four strains

number of dead animals was similar among the four strains. The cause of death was not investigated. The time course of the mean body weight gain is shown in Fig. 3. Although the mean body weight of $h V / h V: h R / h R$ and $h V / h M: h R / h R$ mice was slightly lower at some points, there was no difference at 24 months of age. Food consumption was measured for one week when mice were 6 months of age and was similar among the four mouse strains. In addition, the results of the clinical chemistry and hematology analyses of blood samples were similar among the four strains.

\section{Onset and Degree of Amyloid Fibril Deposition}

Amyloid deposition was not observed in the brain, liver, or spleen of all mouse strains. Amyloid fibrils were stained with the anti-TTR antibody, but not the anti-SAA antibody, suggesting that secondary amyloidosis did not occur under the conventional conditions of the mouse facility.

Amyloid deposition was observed only in the intestinal tract in $+/+: T g$ (Fig. 5a, e, i) and $-/-:$ Tg mice (Fig. 5b, f, j). Amyloid deposition was first found in the alimentary tract at 12 months of age (Fig. 4, Table 1). The amount of amyloid deposits in the alimentary tract was increased with age (Fig. 4, Table 1). However, amyloid deposition in the heart and kidney was not found, even at 24 months of age, in these lines under the conventional conditions used in this study (Table 1). In general, there was less amyloid deposition in this experiment than that previously reported $[15,39]$.

Amyloid deposition was first found in the alimentary tract at 12 months of age in the $h V / h V: h R / h R$ line but at 18 months of age in the $h V / h M: h R / h R$ line (Table 1). Amyloid deposition in the $h V / h V: h R / h R$ and the $h V / h M: h R /$ $h R$ lines at 24 months of age was shown in Fig. 5c, g, and k and Fig. 5d, h, and 1, respectively. In these lines, the amount 
Fig. 4 Amounts of amyloid deposition. a At 12 months of age. Amyloid deposition in the alimentary tract was observed in $+/+: T g,-/-: T g$ and $h V / h V: h R /$ $h R$ lines. b At 18 months of age. Amyloid deposition in the alimentary tract was observed in all lines. c At 24 months of age. The amounts of amyloid deposition in the alimentary tract was higher in the $h V / h V: h R / h R$ and $h V / h M: h R / h R$ lines than those in the $+/+: T g$ and $-/-: T g$ lines. Amyloid deposition in the heart was observed only in the $h V / h V: h R / h R$ and $h V / h M: h R / h R$ lines. Amyloid deposition in the sciatic nerve was observed only in the $h V / h M: h R / h R$ line

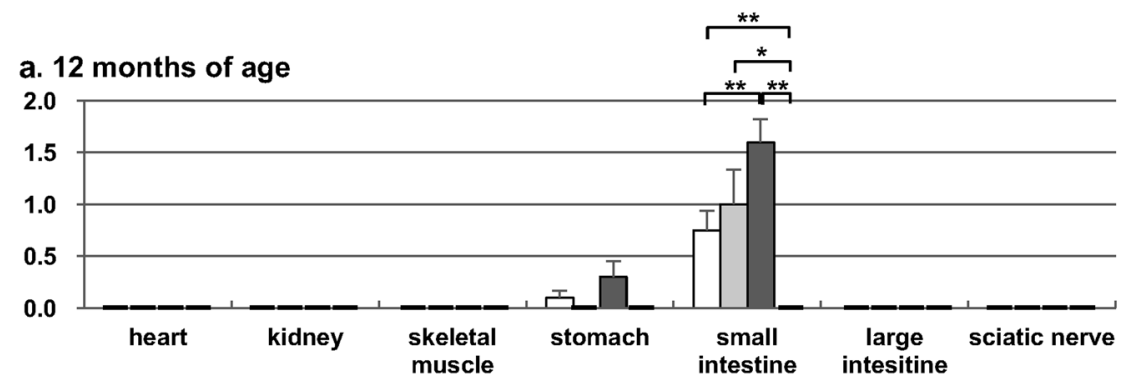

b. 18 months of age

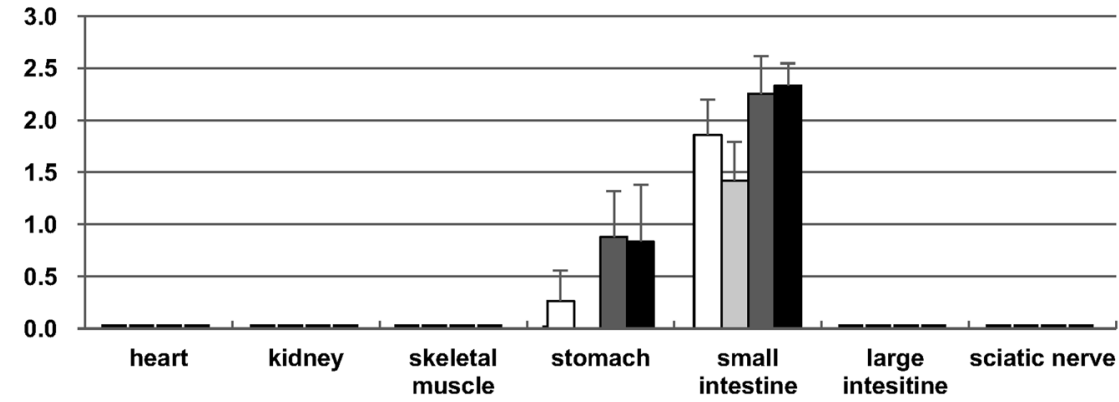

c. 24 months of age

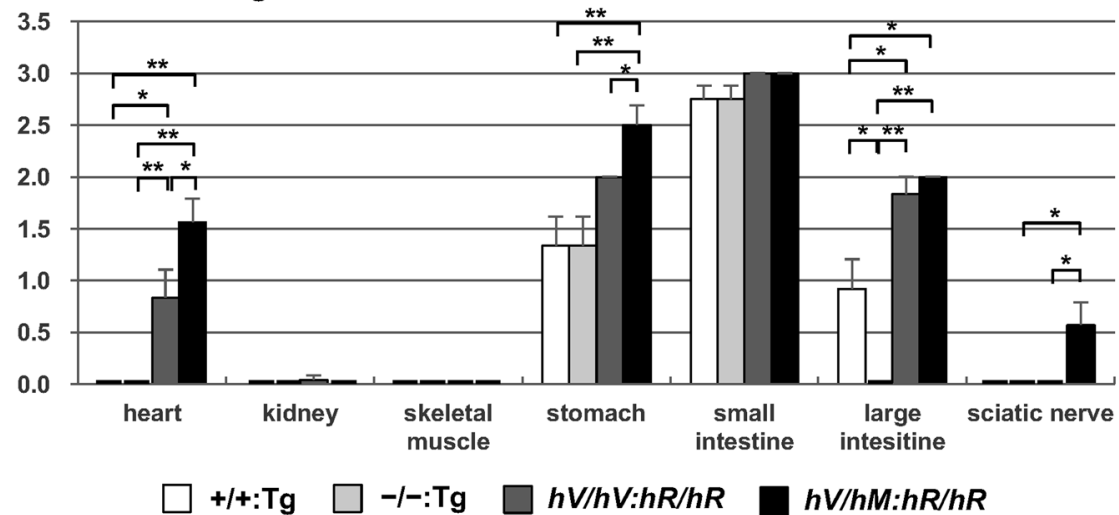

of amyloid deposits in the alimentary tract increased with age and was higher than that in the $+/+: T g$ and $-/-: T g$ lines (Fig. 4, Table 1). Amyloid deposition was first found in the stomach or small intestine and then in the large intestine. The major sites of amyloid deposition in the alimentary tract were similar to those previously described $[15,18]$. In addition, amyloid deposition was observed in the heart in both $h V / h V: h R / h R$ (Fig. $5 \mathrm{~m}, \mathrm{n}$ ) and $h V / h M: h R /$ $h R$ (Fig. 5o, p) strains at 24 months of age, but there were more amyloid deposits in the $h V / h M: h R / h R$ line than in the $h V / h V: h R / h R$ line (Fig. 4). Surprisingly, amyloid deposition was found in the perineurium of the sciatic nerve of the $h \mathrm{~V} /$ $h M: h R / h R$ mice at 24 months of age (Fig. 5q-s; Table 1). We believe that this is the first case of amyloid deposition in the peripheral nerve in the model mouse, although nonfibrillar deposits were observed in $\operatorname{Tg}(6.0$ hTTRV30M): $H s f 1^{-1-}$ (designated as TTR/HSF1) mice [40]. Amyloid deposition in the kidney was observed in only the wall of a small vessel in one $h V / h V: h R / h R$ mouse. Taken together, there was more amyloid deposition in the $h V / h V: h R / h R$ and $h V / h M: h R / h R$ lines than in the $+/+: T g$ and $-/-: T g$ lines. These results were surprising because serum hTTR levels in the $h V / h V: h R / h R$ and $h V / h M: h R / h R$ lines were $\sim 1 / 25$ compared with those in the $+/+: T g$ and $-/-: T g$ lines. These results suggest that the kinetic and thermodynamic stability of the TTR:RBP4 complex is important for amyloid deposition that replicating the human disease.

\section{Assessment of TTR deposition by immunohistochemistry}

We analyzed anti-human TTR-positive deposits by immunohistochemistry at 12,18 , and 24 months of age (Table 2). At 12 months of age, anti-human TTR-positive deposits was observed in the small intestine of all mice except $\mathrm{hV} /$ $\mathrm{hM}: \mathrm{hR} / \mathrm{hR}$ mice in which $30 \%$ of them showed TTRpositive deposits. In the heart and kidneys, 10-30\% of mice showed TTR-positive deposits, while no amyloid fibril 
Table 1 Tissue distribution of TTR amyloid deposits

\begin{tabular}{|c|c|c|c|c|c|}
\hline & & $\operatorname{Ttr}^{+/+}: T g(6.0-h M e t 30)$ & $\operatorname{Ttr}^{-/-}: T g(6.0-h M e t 30)$ & $T t r^{h V a l 30 / h V a l 30}: R b p 4^{h R B P 4 / h R B P 4}$ & $\begin{array}{l}\text { Ttr } \\
R \text { hVal30/hMet30 } \\
R \text { hRBP4/hRBP4 }\end{array}$ \\
\hline \multirow[t]{7}{*}{$12 \mathrm{~m}$} & Heart & $0 / 10$ & $0 / 10$ & $0 / 10$ & $0 / 10$ \\
\hline & Kidney & $0 / 10$ & $0 / 10$ & $0 / 10$ & $0 / 10$ \\
\hline & Skeletal m & $0 / 10$ & $0 / 10$ & $0 / 10$ & $0 / 10$ \\
\hline & Stomach & $2 / 10( \pm, \pm)$ & $0 / 10$ & $3 / 10(1+, 1+, 1+)$ & $0 / 10$ \\
\hline & $\begin{array}{l}\text { Small } \\
\text { intestine }\end{array}$ & $\begin{array}{c}8 / 10( \pm, \pm, \pm, 1+, 1+, 1+, 1 \\
+, 2+)\end{array}$ & $5 / 10(2+, 2+, 2+, 2+, 2+)$ & $\begin{aligned} & 10 / 10(1+, 1+, 1+, 1+, 1+, 2 \\
&+, 2+, 2+, 2+, 3+)\end{aligned}$ & $0 / 10$ \\
\hline & $\begin{array}{l}\text { Large } \\
\text { intestine }\end{array}$ & $0 / 10$ & $0 / 10$ & $0 / 10$ & $0 / 10$ \\
\hline & Sciatic nerve & $0 / 8$ & $0 / 10$ & $0 / 10$ & $0 / 10$ \\
\hline \multirow[t]{7}{*}{$18 \mathrm{~m}$} & Heart & $0 / 7$ & $0 / 7$ & $0 / 8$ & $0 / 6$ \\
\hline & Kidney & $0 / 7$ & $0 / 7$ & $0 / 8$ & $0 / 6$ \\
\hline & Skeletal m & $0 / 7$ & $0 / 7$ & $0 / 8$ & $0 / 6$ \\
\hline & Stomach & $1 / 7(2+)$ & $0 / 7$ & $3 / 8(2+, 3+, 3+)$ & $2 / 6(2+, 3+)$ \\
\hline & $\begin{array}{l}\text { Small } \\
\text { intestine }\end{array}$ & $\begin{array}{c}6 / 7(2+, 2+, 2+, 2+, 2+, 3 \\
+)\end{array}$ & $5 / 7(2+, 2+, 2+, 2+, 2+)$ & $7 / 8\left(2+, 2+, \begin{array}{c}2+, 3+, 3+, 3+, \\
3+)\end{array}\right.$ & $\begin{array}{c}6 / 6(2+, 2+, 2+, 2+, 3 \\
+, 3+)\end{array}$ \\
\hline & $\begin{array}{l}\text { Large } \\
\text { intestine }\end{array}$ & $0 / 7$ & $0 / 7$ & $0 / 7$ & $0 / 6$ \\
\hline & Sciatic nerve & $0 / 7$ & $0 / 7$ & $0 / 7$ & $0 / 6$ \\
\hline \multirow[t]{7}{*}{$24 \mathrm{~m}$} & Heart & $0 / 12$ & $0 / 12$ & $6 / 12(1+, 1+, 2+, 2+, 2+, 2+)$ & $\begin{array}{c}8 / 8( \pm, 1+, 1+, 2+, 2+, \\
2+, 2+, 2+)\end{array}$ \\
\hline & Kidney & $0 / 12$ & $0 / 12$ & $1 / 12( \pm)$ & $0 / 8$ \\
\hline & Skeletal m & $0 / 12$ & $0 / 11$ & $0 / 12$ & $0 / 8$ \\
\hline & Stomach & $\begin{array}{c}8 / 12(2+, 2+, 2+, 2+, 2+, 2 \\
+, 2 ;, 2+)\end{array}$ & $\begin{array}{c}8 / 11(2+, 2+, 2+, 2+, 2+, 2 \\
+, 2+, 2+)\end{array}$ & $\begin{array}{c}12 / 12(2+, 2+, 2+, 2+, 2+, 2 \\
+, 2+, 2+, 2+, 2+, 2+, 2+)\end{array}$ & $\begin{array}{c}8 / 8(2+, 2+, 2+, 2+, 3 \\
\quad+, 3+, 3+, 3+)\end{array}$ \\
\hline & $\begin{array}{l}\text { Small } \\
\text { intestine }\end{array}$ & $\begin{array}{c}12 / 12(2+, 2+, 2+, 3+, 3+, \\
3+, 3+, 3+, 3+, 3+, 3+, 3 \\
+)\end{array}$ & $\begin{array}{c}12 / 12(2+, 2+, 2+, 3+, 3+, \\
3+, 3+, 3+, 3+, 3+, 3+, 3 \\
+)\end{array}$ & $\begin{array}{c}12 / 12(3+, 3+, 3+, 3+, 3+, 3 \\
+, 3+, 3+, 3+, 3+, 3+, 3+)\end{array}$ & $\begin{array}{c}8 / 8(3+, 3+, 3+, 3+, 3 \\
\quad+, 3+, 3+, 3+)\end{array}$ \\
\hline & $\begin{array}{l}\text { Large } \\
\text { intestine }\end{array}$ & $\begin{array}{c}6 / 12(1+, 2+, 2+, 2+, 2+, 2 \\
+)\end{array}$ & $0 / 12$ & $\begin{array}{c}11 / 12(2+, 2+, 2+, 2+, 2+, 2 \\
+, 2+, 2+, 2+, 2+, 2+)\end{array}$ & $\begin{array}{c}8 / 8(2+, 2+, 2+, 2+, 2 \\
\quad+, 2+, 2+, 2+)\end{array}$ \\
\hline & Sciatic nerve & $0 / 12$ & $0 / 9$ & $0 / 12$ & $4 / 7(1+, 1+, 1+, 1+)^{*}$ \\
\hline
\end{tabular}

- no amyloid deposits, \pm deposition limited to the walls of small vessels, + deposition in walls of small vessels and surrounding areas, ++ moderate deposition in interstitium, +++ marked deposition in interstitium and parenchyma.

*Positive in epineurium

deposits were observed. At 18 months of age, anti-human TTR-positive deposits was observed in the small intestine of all mice. In the heart and kidneys, 30-50\% of mice showed TTR-positive deposits, while no amyloid fibril deposits were observed. At 24 months of age, anti-human TTRpositive deposits was observed in the small intestine of all mice. In the heart and kidneys, 30-100\% of mice showed TTR-positive deposits. Thus, anti-human TTR-positive deposits were found in earlier age and higher percentage in all strains than amyloid fibril deposits.

\section{Gel filtration chromatography}

To analyze the kinetic and thermodynamic stability of the TTR:RBP4 complex, plasma samples from $+/+, h V / h V: h R /$ $h R$ and $h V / h M: h R / h R$ mice were subjected to gel filtration chromatography, and column fractions were analyzed by western blotting. The majority of immunoreactive RBP4 and TTR eluted together in fractions $28-31$ in the control mouse (Fig. 6). A small amount of immunoreactive RBP4 eluted after this primary peak in subsequent fractions 32-39 (Fig. 6). These secondary fractions represent non-TTRbound RBP4 because no associated TTR immunoreactivity was observed (Fig. 6). The percentage of the TTR-RBP4 bound form in $+/+$ mice was $82.0 \pm 2.2$ (Fig. 6). However, most of the RBP4 in the $h V / h V: h R / h R$ and $h V / h M: h R / h R$ mice were not bound to TTR, indicating that the hTTR was also free. These results suggest that the increase in free hTTR accelerates amyloid deposition, even under conditions of low serum hTTR levels. 


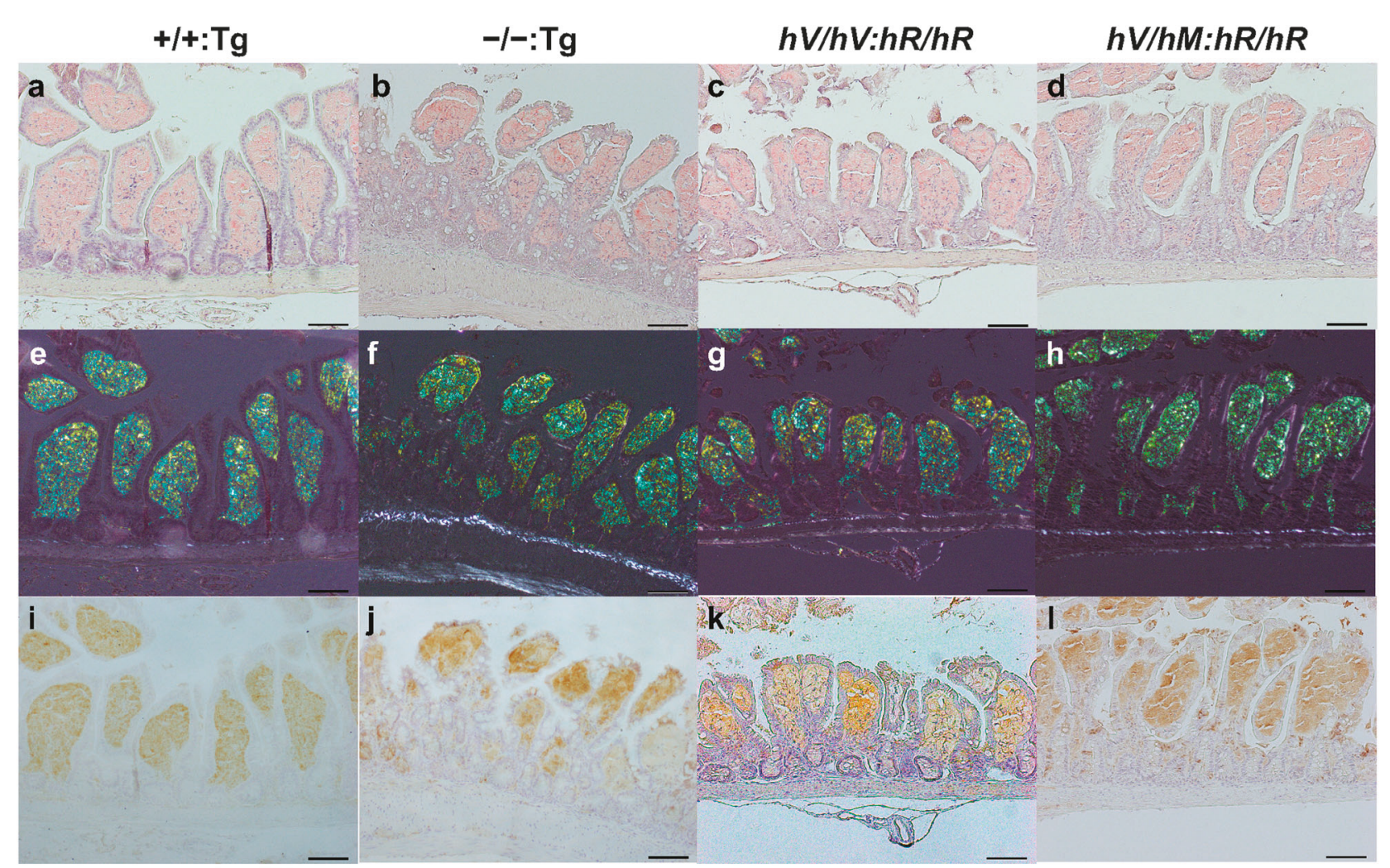

\section{$h V / h V: h R / h R$}
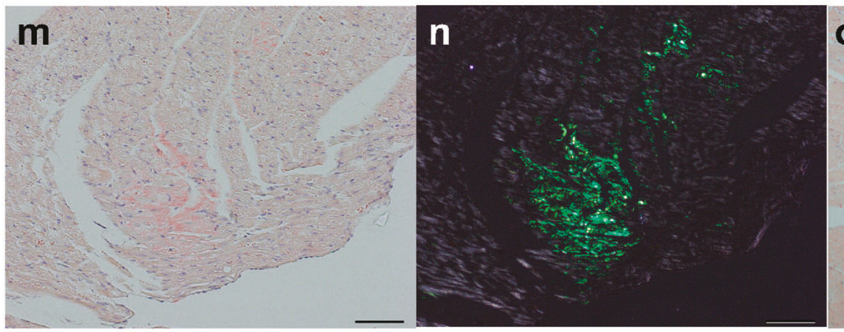

$h V / h M: h R / h R$

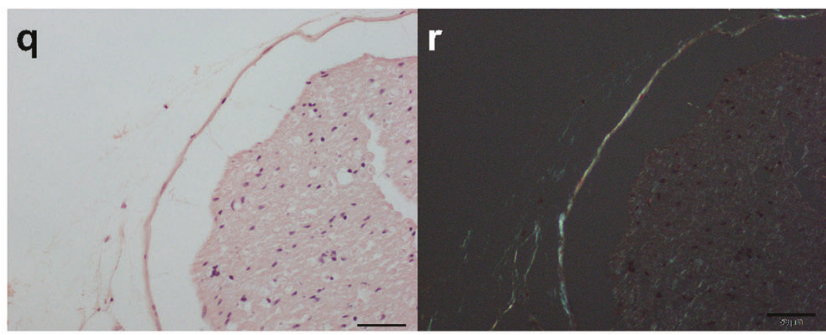

Fig. 5 Histochemical and immunohistochemical analyses. Histochemical and immunohistochemical findings at 24 months of age in the small intestine $(\mathbf{a}-\mathbf{l})$, the heart $(\mathbf{m}-\mathbf{p})$, and the sciatic nerve $(\mathbf{q}-\mathbf{s})$. The sections stained with Congo Red (a-d, $\mathbf{m}, \mathbf{o}$, and $\mathbf{q})$ showed apple green birefringence under polarizing light $(\mathbf{e}-\mathbf{h}, \mathbf{n}, \mathbf{p}$, and $\mathbf{r})$. Tissue sections were also stained with anti-human TTR (i-l, and s). Amyloid deposition was observed only in the intestinal tract in $+/+: \operatorname{Tg}(\mathbf{a}, \mathbf{e}$,

\section{$h V / h M: h R / h R$}
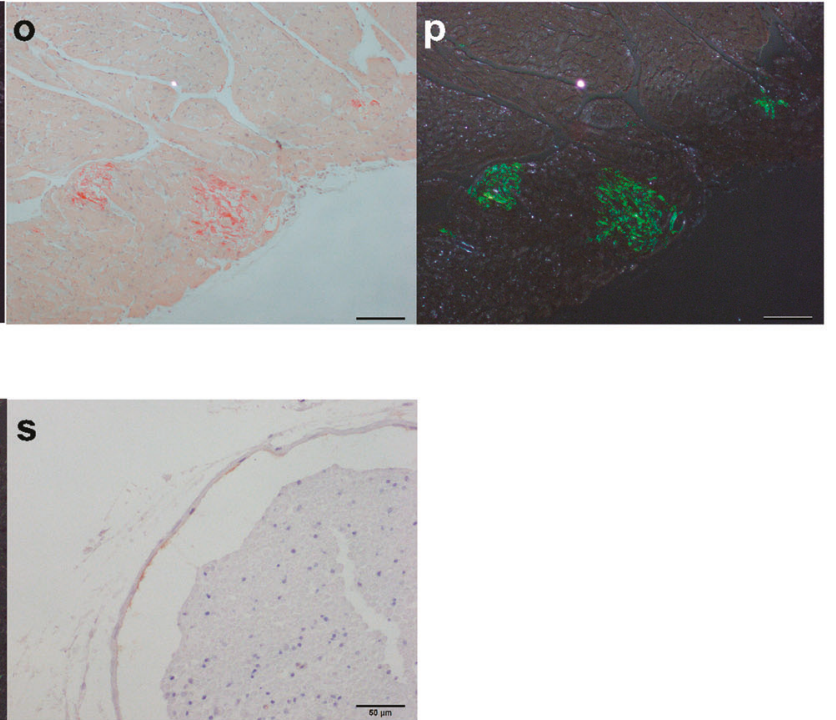

and $\mathbf{i})$ and $-/-: T g$ mice $(\mathbf{b}, \mathbf{f}$, and $\mathbf{j})$. By contrast, amyloid deposition was observed in the intestinal tract $(\mathbf{c}, \mathbf{g}$, and $\mathbf{k})$ and heart ( $\mathbf{m}$ and $\mathbf{n})$ in $h V / h V: h R / h R$ mice and in the intestinal tract (d, $\mathbf{h}$, and $\mathbf{l})$, heart, (o and p) and sciatic nerve $(\mathbf{q}-\mathbf{s})$ in $h V / h M: h R / h R$ mice. Scale bar: $100 \mu \mathrm{m}$ in $\mathbf{a}-\mathbf{p}$ and $50 \mu \mathrm{m}$ in $\mathbf{q}-\mathbf{s}$ 
Table 2 Anti-TTR antibodypositive and amyloid fibril tissue deposition

\begin{tabular}{|c|c|c|c|c|c|c|c|c|c|}
\hline \multirow[t]{2}{*}{ Age } & \multirow[t]{2}{*}{ Strain } & \multicolumn{2}{|c|}{$+/+: \mathrm{Tg}$} & \multicolumn{2}{|c|}{$-/-: \mathrm{Tg}$} & \multicolumn{2}{|c|}{$\mathrm{hV} / \mathrm{hV}: \mathrm{hR} / \mathrm{hR}$} & \multicolumn{2}{|c|}{ hV/hM:hR/hR } \\
\hline & & TTR+ & $\mathrm{CR}+$ & TTR+ & $\mathrm{CR}+$ & TTR+ & $\mathrm{CR}+$ & TTR+ & $\mathrm{CR}+$ \\
\hline \multirow[t]{4}{*}{12 months } & Small intestine & $10 / 10$ & $8 / 10$ & $8 / 10$ & $5 / 10$ & $10 / 10$ & $10 / 10$ & $3 / 10$ & $0 / 10$ \\
\hline & Heart & $3 / 10$ & $0 / 10$ & $3 / 10$ & $0 / 10$ & $2 / 10$ & $0 / 10$ & $1 / 10$ & $0 / 10$ \\
\hline & Kidney & $2 / 10$ & $0 / 10$ & $2 / 10$ & $0 / 10$ & $1 / 10$ & $0 / 10$ & $1 / 10$ & $0 / 10$ \\
\hline & Sciaic nerve & $0 / 8$ & $0 / 8$ & $0 / 10$ & $0 / 10$ & $0 / 10$ & $0 / 10$ & $0 / 10$ & $0 / 10$ \\
\hline \multirow[t]{4}{*}{18 months } & Small intestine & $7 / 7$ & $6 / 7$ & $6 / 7$ & $5 / 7$ & $8 / 8$ & $7 / 8$ & $6 / 6$ & $6 / 6$ \\
\hline & Heart & $2 / 7$ & $0 / 7$ & $2 / 7$ & $0 / 7$ & $3 / 8$ & $0 / 8$ & $4 / 6$ & $0 / 6$ \\
\hline & Kidney & $2 / 7$ & $0 / 7$ & $3 / 7$ & $0 / 7$ & $3 / 8$ & $0 / 8$ & $3 / 6$ & $0 / 6$ \\
\hline & Sciaic nerve & $2 / 7$ & $0 / 7$ & $1 / 7$ & $0 / 7$ & $0 / 7$ & $0 / 7$ & $0 / 6$ & $0 / 6$ \\
\hline \multirow[t]{4}{*}{24 months } & Small intestine & $12 / 12$ & $12 / 12$ & $12 / 12$ & $12 / 12$ & $12 / 12$ & $12 / 12$ & $8 / 8$ & $8 / 8$ \\
\hline & Heart & $5 / 12$ & $0 / 12$ & $4 / 12$ & $0 / 12$ & $8 / 12$ & $6 / 12$ & $8 / 8$ & $8 / 8$ \\
\hline & Kidney & $4 / 12$ & $0 / 12$ & $3 / 12$ & $0 / 12$ & $3 / 12$ & $1 / 12$ & $4 / 8$ & $0 / 8$ \\
\hline & Sciaic nerve & $2 / 12$ & $0 / 12$ & $1 / 9$ & $0 / 9$ & $2 / 12$ & $0 / 12$ & $5 / 7$ & $4 / 7$ \\
\hline
\end{tabular}

$T T R+$ anti-TTR antibody-positive, $C R+$ congo red positive

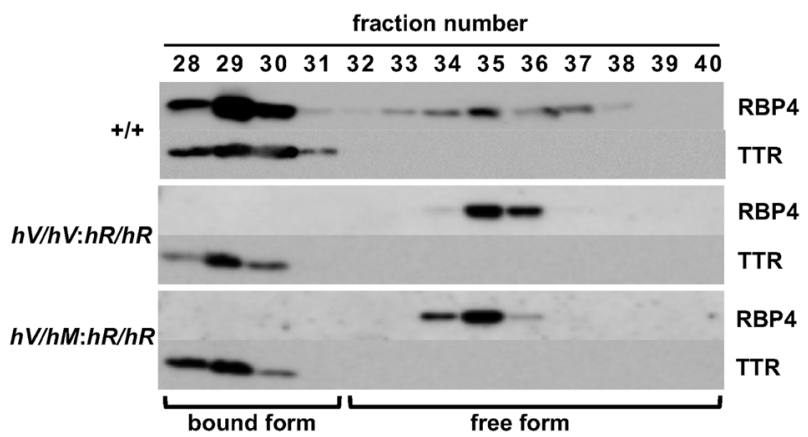

Fig. 6 Gel filtration chromatography. Each fraction was analyzed by western blotting using anti-RBP4 and anti-TTR antibodies. The bound form of RBP4 and TTR was found in fractions 28-31, whereas the free form of RBP4 was found in fractions 32-39. The TTR-RBP4 complex was barely detected in the $h V / h V: h R / h R$ and $h V / h M: h R / h R$ lines

\section{Discussion}

In this study, we analyzed amyloid deposition in two double-humanized mouse strains, $h V / h V: h R / h R$ and $h V / h M$ : $h R / h R$. The serum levels of hTTR and hRBP4 were much lower in the double-humanized mice than in conventional transgenic mice, $\operatorname{Tg}(6.0-\mathrm{hMet} 30)$, on the wild-type Ttr or the $T t r$-null background. Nevertheless, amyloid deposition was more prominent in $h V / h V: h R / h R$ and $h V / h M: h R / h R$ mice than in conventional transgenic mice. In addition, amyloid deposition was also observed in $h V / h V: h R / h R$ mice, carrying the normal human TTR gene. Amyloid deposition started later in $h V / h M: h R / h R$ mice than in $h V / h V$ : $h R / h R$ mice, but $h V / h M: h R / h R$ showed more amyloid deposition at 24 months of age. Furthermore, amyloid deposition was first observed in the sciatic nerve without any additional genetic change.
Previously, we reported no amyloid deposition in transgenic mice carrying the wild-type $h T T R$ gene (designated as C57BL/6-Tg(7.2TTRVal30)) [14]. By contrast, non-fibrillar deposits were reported in mice transgenic for the wild-type hTTR gene (designated as B6D2F2-Tg(19.2TTRVal30)) by other investigators [16, 41]. Serum concentrations of $\mathrm{hVal} 30$ were $26-80 \mu \mathrm{g} / \mathrm{ml}$ in C57BL/6-Tg(7.2TTRVal30) mice and $1-3.5 \mathrm{mg} / \mathrm{ml}$ in B6D2F2-Tg(19.2TTRVal30) mice. As the serum levels of $\mathrm{hVal} 30$ in B6D2F2-Tg (19.2TTRVal30) mice were 10-100 times higher than those in C57BL/6- $\operatorname{Tg}(7.2 T T R V a l 30)$ mice, the high Val30 expression was thought to be required for amyloid deposition of wild-type hTTR. However, the serum concentration of hTTR in our $h V / h V: h R / h R$ mice was $6.62 \pm 0.37 \mu \mathrm{g} / \mathrm{ml}$, 10-fold lower than that in C57BL/6-Tg(7.2TTRVal30) mice and 100-fold lower than that in B6D2F2-Tg (19.2TTRVal30) mice. We also reported that the serum levels of human mutant TTR are correlated, to some extent, with the occurrence and degree of amyloid deposition in C57BL/6-Tg(7.2TTRVal30) mice [15]. However, amyloid deposition was more prominent in $h V / h V: h R / h R$ and $h V / h M$ : $h R / h R$ mice than in $+/+: T g$ and $-/-: T g$ mice. Furthermore, we are the first to observe amyloid deposition in the sciatic nerve without additional genetic change, such as $H s f$ deficiency, in the $h V / h M: h R / h R$ line.

As reported by other investigators [12, 13, 16], anti-TTR antibody-positive deposits were found in earlier age and higher percentage in all our mice than amyloid fibril deposits. Teng et al. demonstrated that both amyloid and nonamyloid deposits were intact human TTR monomers with no evidence of proteolysis by amino terminal amino acid sequence analysis and mass spectrometry [16]. Thus, the anti-TTR antibody-positive deposits may represent a preamyloid intermediate state. 
In our models, the mouse Ttr and Rbp4 genes were replaced with the human $T T R$ and $R B P 4$ genes, respectively. Thus, there is no expression of mouse TTR. It is well known that heterotetramers of human and mouse TTR are present in the serum of these transgenic mice and that these heterotetramers are more stable than hTTR homotetramers [19]. In fact, amyloid deposition was accelerated by TTR-Leu55Pro on a Ttr-null background (designated as $\mathrm{Ttr}^{-/-}: 129 \mathrm{~S} 1 / \mathrm{Sv}-\mathrm{Tg}$ (TTRPro55)] [12] or $\mathrm{Ttr}^{-1-}$ :B6D2F2-Tg(TTRPro55) [13]). By contrast, Kohno et al. [35] demonstrated no differences in the onset, progression, or tissue distribution of amyloid deposition in $\operatorname{Tg}(6.0$ TTTRMet30) mice with or without the murine $T t r$ gene (designated as $T_{t r}{ }^{+/+}$:C57BL/6-Tg (6.0hTTRMet30) or $\left.\mathrm{Ttr}^{-1-}: \mathrm{Tg}(\mathrm{C} 57 \mathrm{BL} / 6-6.0 h T T R M e t 30)\right)$. The serum levels of TTRPro55 in $\mathrm{Ttr}^{-/}: 129 \mathrm{~S} 1 / \mathrm{Sv}-\mathrm{Tg}$ (TTRPro55), Ttr $^{-/-}: \mathrm{B} 6 \mathrm{D} 2 \mathrm{~F} 2-\mathrm{Tg}\left(\right.$ TTRPro55), and $\mathrm{Ttr}^{-1-}: \mathrm{Tg}$ (C57BL/6-6.0hTTRMet30) mice were 10-200, 20-35, and $240-340 \mu \mathrm{g} / \mathrm{ml}$, respectively. These data suggest that amyloid deposition was affected by the presence or absence of mouse Ttr under conditions of low serum levels of human mutant TTR. Amyloid deposition may be facilitated by the absence of mouse TTR, probably because of the instability of human TTR tetramers. Interestingly, hTTRVal30 and hTTRMet30 tetramers are more unstable in mouse serum, when the serum human TTR levels were low [31]. Human $T T R$ mRNA and TTR protein expression levels in the liver of homozygous $h V / h V$ mice were approximately twice those in heterozygous $+/ h V$ mice. However, the serum human TTR levels were much lower in $h V / h V$ mice than in $+/ h V$ mice. The low mean serum hTTR levels could be due to shunting to the ERAD pathway. In a previous study [31], we examined morphological abnormality by transmission electronmicroscopy and the localization of hTTR using immunofluorescent detection with anti-calnexin and antiGM130 antibodies. We did not find any abnormality, suggesting that hTTR was secreted by normal pathway.

RBP4 may also influence the amyloid deposition. As we reported previously, the serum level of hRBP4 in $R b p 4^{h R / h R}$ $(h R / h R)$ mice was $7.4 \pm 1.50 \mu \mathrm{g} / \mathrm{ml}$ [32], whereas the serum levels of hRBP4 levels in $h V / h V: h R / h R$ and $h V / h M: h R / h R$ mice were $0.60 \pm 0.05$ and $0.46 \pm 0.02 \mu \mathrm{g} / \mathrm{ml}$, respectively, indicating a considerable reduction in these mice with serum hTTR levels $\sim 1 / 25$ of normal. This decrease in RBP4 may be due to glomerular filtration of non-TTR-bound RBP4. As shown in Fig. 6, the hTTR-bound form of hRBP4 was barely detected, although $\sim 80-90 \%$ of RBP4 is TTR bound under normal conditions [32, 42]. Thus, an increase in non-RBP4-bound TTR potentially accelerated amyloid deposition in our double-humanized mice. In fact, RBP4 can prevent TTR amyloid formation at acidic $\mathrm{pH}$ [43].

To the best of our knowledge, neither non-fibrillar nor fibrillary deposits have been observed in the peripheral and autonomic nervous systems of conventional TTR transgenic mouse models. Non-fibrillar deposits accompanied by the induction of pro-inflammatory cytokines, RAGE up-regulation, and NF- $\kappa \mathrm{B}$ activation were first reported in the sciatic nerve, dorsal root ganglia (DRG), and autonomic ganglia of $\operatorname{Tg}(6.0 h T T R V 30 M): H s f 1^{-/}$(designated as TTR/ HSF 1) mice [40]. This result suggested that disrupting the heat shock response would aggravate TTR deposition and that HSF1 is involved in famial amyloidotic polyneuropathy (FAP) pathogenesis as a defense mechanism against extracellular TTR deposits. In our $h V / h M: h R / h R$ mice, we observed amyloid deposition in the perineurium of the sciatic nerve. However, no such inflammatory response was observed in our $h V / h M: h R / h R$ mice. The inflammatory response might be important for neurodegeneration, but the physico-chemical properties of the TTR-RBP4 complex in the microenvironment surrounding the peripheral nerve or autonomic nerve may be important for non-fibrillar and fibrillary deposits.

We previously reported that amyloid deposition was observed in the heart and kidney of the $+/+: T g$ and $-/-: T g$ lines $[15,35]$. However, this result was not reproduced in this experiment, perhaps because of different housing conditions, as amyloid deposition is greatly affected by environmental conditions [39]. The amount of amyloid deposits differs under various conventional conditions [44].

In human, serum levels of TTR decreased with aging [45-47]. Kohno et al. [35] examined the serum hTTR levels in $+/+: \operatorname{Tg}$ and $-/-: \mathrm{Tg}$ strains at 11,14 , and 18 months of age, but there was no significant difference among age groups. We also examined the serum levels of hTTR, mRBP4, and hRBP4 at 12 and 24 months of age. However, there was no significant difference among age groups in all mouse strains. It is known that the serum TTR level is a good biomarker for nutritional state [48, 49]. As experimental mice are kept in good housing conditions, the serum TTR levels may not change under such conditions.

Gel filtration assay revealed that most hRBP4 was free of hTTR. Free hRBP4 was easily excreted to urine due to its small protein size. However, serum RBP4 levels were $0.5-0.6 \mu \mathrm{g} / \mathrm{ml}$ and the ratio of RBP4 to TTR $(5.7-7.5 \mathrm{ug} / \mathrm{ml})$ was about 1:10 in our double-humanized mice. This ratio is similar to human status which is $1 / 5$ to $1 / 10$. Thus, we do not know why the hTTR/hRBP4 ratio was kept within normal range despite most hRBP4 was free of hTTR. Before gel filtration assay, the serum sample was diluted two times with phosphate buffer. This treatment may cause dissociation of TTR/RBP4 complex, especially when TTR and RBP4 concentration is low.

Taken together, the presence of human RBP4 instead of mouse RBP4 and the absence of mouse TTR might be responsible for the accelerated amyloid deposition in our $h V / h V: h R / h R$ mice despite the low serum hTTR level. These data suggest that our models recapitulated the pathological 
findings in FAP more precisely. In addition, this model will be necessary for the appropriate evaluation of effective therapeutics. However, our mice does not represent human TTR status as far as the low serum hTTR level and high percentage of unbound TTR with RBP4 are concerned. In our double-humanized mice, mean serum RBP4 levels were $0.5-0.6 \mu \mathrm{g} / \mathrm{ml}$ and the ratio of RBP4 to TTR was $\sim 1: 10$. This ratio is similar to that of the human situation $(1 / 5-1 /$ 10). We wondered whether amyloid deposition occurred under such a low serum level of hTTR. RNA interference (RNAi) therapy is now under investigation. In this case, we expect very low level of serum hTTR and RBP4. So, the question is that can we stop amyloid deposition by lowering the hTTR expression. Serum level of hTTR in our mice is $1 /$ 25 of that in human. Thus, our data might be useful to consider the effect of RNAi therapy. The double-humanized mouse at the Ttr and Rbp4 loci, in which serum TTR and RBP4 levels are equivalent to those in humans, represents a promising approach to replicating more precisely the disease process.

Acknowledgements The manuscript has been carefully edited by Nature Research Editing Service (http://authorservices.springernature. com). This study was partly funded by Chiesi Farmaceutici, Parma, Italy. This work was supported by Grants-in-Aid for Scientific Research (24590404 to Z.L.) and (S) (21220010 to K.Y.) from the Japan Society for the Promotion of Science, the National Natural Science Foundation of China (grant number 81670028 to S.J.), the Major Program of Natural Science Foundation of Heilongjiang Province of China (ZD2016014 to S.J.); the Dean Foundation and Foster Foundation of the Fourth Hospital of Harbin Medical University (to S. J.); Scientific Support Programs for Cancer Research, a Grant-in-Aid for Scientific Research on Innovative Areas, the Ministry of Education, Culture, Sports, Science and Technology (221S0001 to K.Y.); and CREST (Japan Science and Technology Agency) (to K.Y.).

\section{Compliance with ethical standards}

Conflict of interest The authors declare that they have no conflict of interest.

\section{References}

1. Schreiber G. The evolution of transthyretin synthesis in the choroid plexus. Clin Chem Lab Med. 2002;40:1200-10.

2. Vranckx R, Savu L, Maya M, et al. Characterization of a major development-regulated serum thyroxine-binding globulin in the euthyroid mouse. Biochem J. 1990;271:373-9.

3. Colon W, Kelly JW. Partial denaturation of transthyretin is sufficient for amyloid fibril formation in vitro. Biochemistry. 1992;31:8654-60.

4. Hammarstrom P, Jiang X, Hurshman AR, et al. Sequencedependent denaturation energetics: A major determinant in amyloid disease diversity. Proc Natl Acad Sci USA. 2002;99(Suppl 4):16427-32.

5. Lai Z, Colon W, Kelly JW. The acid-mediated denaturation pathway of transthyretin yields a conformational intermediate that can self-assemble into amyloid. Biochemistry. 1996;35:6470-82.
6. Johnson SM, Petrassi HM, Palaninathan SK, et al. Bisaryloxime ethers as potent inhibitors of transthyretin amyloid fibril formation. J Med Chem. 2005;48:1576-87.

7. Klabunde T, Petrassi HM, Oza VB, et al. Rational design of potent human transthyretin amyloid disease inhibitors. Nat Struct Biol. 2000;7:312-21.

8. Miroy GJ, Lai Z, Lashuel HA, et al. Inhibiting transthyretin amyloid fibril formation via protein stabilization. Proc Natl Acad Sci USA. 1996;93:15051-6.

9. Sekijima Y, Kelly JW, Ikeda S. Pathogenesis of and therapeutic strategies to ameliorate the transthyretin amyloidoses. Curr Pharm Des. 2008;14:3219-30.

10. Tojo K, Sekijima Y, Kelly JW, et al. Diflunisal stabilizes familial amyloid polyneuropathy-associated transthyretin variant tetramers in serum against dissociation required for amyloidogenesis. Neurosci Res. 2006;56:441-9.

11. Zanotti G, Cendron L, Folli C, et al. Structural evidence for native state stabilization of a conformationally labile amyloidogenic transthyretin variant by fibrillogenesis inhibitors. FEBS Lett. 2013;587:2325-31.

12. Sousa MM, Fernandes R, Palha JA, et al. Evidence for early cytotoxic aggregates in transgenic mice for human transthyretin Leu55Pro. Am J Pathol. 2002;161:1935-48.

13. Tagoe CE, Reixach N, Friske L, et al. In vivo stabilization of mutant human transthyretin in transgenic mice. Amyloid. 2007;14:227-36.

14. Takaoka Y, Ohta M, Miyakawa $\mathrm{K}$, et al. Cysteine 10 is a key residue in amyloidogenesis of human transthyretin Val30Met. Am J Pathol. 2004;164:337-45.

15. Takaoka Y, Tashiro F, Yi S, et al. Comparison of amyloid deposition in two lines of transgenic mouse that model familial amyloidotic polyneuropathy, type I. Transgenic Res. 1997;6:261-9.

16. Teng MH, Yin JY, Vidal R, et al. Amyloid and nonfibrillar deposits in mice transgenic for wild-type human transthyretin: a possible model for senile systemic amyloidosis. Lab Invest. 2001;81:385-96.

17. Watts RP, Umemichi T, Zeldenrust SR, et al. Development of lines of transgenic mice expressing the human transthyretin Ser84 variant. Neuromuscul Disord. 1996;6:S31.

18. Yi S, Takahashi K, Naito $\mathrm{M}$, et al. Systemic amyloidosis in transgenic mice carrying the human mutant transthyretin (Met30) gene. Pathologic similarity to human familial amyloidotic polyneuropathy, type I. Am J Pathol. 1991;138:403-12.

19. Reixach N, Foss TR, Santelli E, et al. Human-murine transthyretin heterotetramers are kinetically stable and non-amyloidogenic: A lesson in the generation of transgenic models of diseases involving oligomeric proteins. J Biol Chem. 2007;283:2098-107.

20. Adams D, Samuel D, Goulon-Goeau C, et al. The course and prognostic factors of familial amyloid polyneuropathy after liver transplantation. Brain. 2000;123:1495-504.

21. Cavallaro T, Martone RL, Dwork AJ, et al. The retinal pigment epithelium is the unique site of transthyretin synthesis in the rat eye. Invest Ophthalmol Vis Sci. 1990;31:497-501.

22. Kerschen P, Plante-Bordeneuve V. Current and future treatment approaches in transthyretin familial amyloid polyneuropathy. Curr Treat Options Neurol. 2016;18:53.

23. Nowak G, Suhr OB, Wikstrom L, et al. The long-term impact of liver transplantation on kidney function in familial amyloidotic polyneuropathy patients. Transpl Int. 2005;18:111-5.

24. Ohya Y, Okamoto S, Tasaki M, et al. Manifestations of transthyretin-related familial amyloidotic polyneuropathy: longterm follow-up of Japanese patients after liver transplantation. Surg Today. 2011;41:1211-8.

25. Okumura K, Yamashita T, Masuda T, et al. Long-term outcome of patients with hereditary transthyretin V30M amyloidosis with 
polyneuropathy after liver transplantation. Amyloid. 2016;23:39-45.

26. Suhr OB, Anan I, Ahlstrom KR, et al. Gastric emptying before and after liver transplantation for familial amyloidotic polyneuropathy, Portuguese type (Val30Met). Amyloid. 2003;10:121-6.

27. Berk JL, Suhr OB, Obici L, et al. Repurposing diflunisal for familial amyloid polyneuropathy: a randomized clinical trial. Jama. 2013;310:2658-67.

28. Berk JL, Suhr OB, Sekijima Y, et al. The diflunisal trial: study accrual and drug tolerance. Amyloid. 2012;19(Suppl 1):37-38.

29. Coelho T, Maia LF, da Silva AM, et al. Long-term effects of tafamidis for the treatment of transthyretin familial amyloid polyneuropathy. J Neurol. 2013;260:2802-14.

30. Coelho T, Maia LF, Martins da Silva A, et al. Tafamidis for transthyretin familial amyloid polyneuropathy: a randomized, controlled trial. Neurology. 2012;79:785-92.

31. Zhao G, Li Z, Araki K, et al. Inconsistency between hepatic expression and serum concentration of transthyretin in mice humanized at the transthyretin locus. Genes Cells. 2008;13:1257-68.

32. Liu L, Suzuki T, Shen J, et al. Rescue of retinal morphology and function in a humanized mouse at the mouse retinol-binding protein locus. Lab Invest. 2017;97:395-408.

33. Mu Y, Jin S, Shen J, et al. CHF5074 (CSP-1103) stabilizes human transthyretin in mice humanized at the transthyretin and retinolbinding protein loci. FEBS Lett. 2015;589:849-56.

34. Shen J, Shi D, Suzuki T, et al. Severe ocular phenotypes in Rbp4deficient mice in the C57BL/6 genetic background. Lab Invest. 2016;96:680-91.

35. Kohno K, Palha JA, Miyakawa K, et al. Analysis of amyloid deposition in a transgenic mouse model of homozygous familial amyloidotic polyneuropathy. Am J Pathol. 1997;150:1497-508.

36. Yagi T, Tokunaga T, Furuta Y, et al. A novel ES cell line, TT2, with high germline-differentiating potency. Anal Biochem. 1993;214:70-76.

37. Araki K, Imaizumi T, Okuyama K, et al. Efficiency of recombination by $\mathrm{Cre}$ transient expression in embryonic stem cells: comparison of various promoters. J Biochem. 1997;122: 977-82.
38. Nagata Y, Tashiro F, Yi S, et al. A 6-kb upstream region of the human transthyretin gene can direct developmental, tissue-specific, and quantitatively normal expression in transgenic mouse. J Biochem. 1995; 117:169-75.

39. Inoue $\mathrm{S}$, Ohta $\mathrm{M}, \mathrm{Li} \mathrm{Z}$, et al. Specific pathogen free conditions prevent transthyretin amyloidosis in mouse models. Transgenic Res. 2008;17:817-26.

40. Santos SD, Fernandes R, Saraiva MJ. The heat shock response modulates transthyretin deposition in the peripheral and autonomic nervous systems. Neurobiol Aging. 2010;31:280-9.

41. Tagoe CE, Jacobson DR, Gallo G, et al. Mice transgenic for human TTR have the same frequency of renal TTR deposition whether maintained in conventional or specific pathogen free environments. Amyloid. 2003;10:262-6.

42. Mody N, Graham TE, Tsuji Y, et al. Decreased clearance of serum retinol-binding protein and elevated levels of transthyretin in insulin-resistant ob/ob mice. Am J Physiol Endocrinol Metab. 2008;294:E785-793.

43. White JT, Kelly JW. Support for the multigenic hypothesis of amyloidosis: the binding stoichiometry of retinol-binding protein, vitamin A, and thyroid hormone influences transthyretin amyloidogenicity in vitro. Proc Natl Acad Sci USA. 2001;98:13019-24.

44. Noguchi H, Ohta M, Wakasugi S, et al. Effect of the intestinal flora on amyloid deposition in a transgenic mouse model of familial amyloidotic polyneuropathy. Exp Anim. 2002;51:309-16.

45. Benvenga S, Bartalena L, Antonelli A, et al. Radioimmunoassay for human thyroxine-binding prealbumin. Ann Clin Lab Sci. 1986;16:231-40.

46. Ritchie RF, Palomaki GE, Neveux LM, et al. Reference distributions for the negative acute-phase serum proteins, albumin, transferrin and transthyretin: a practical, simple and clinically relevant approach in a large cohort. J Clin Lab Anal. 1999;13:273-9.

47. Tietz NW, Shuey DF, Wekstein DR. Laboratory values in fit aging individuals--sexagenarians through centenarians. Clin Chem. 1992;38:1167-85.

48. Delliere S, Cynober L. Is transthyretin a good marker of nutritional status? Clin Nutr. 2017;36:364-70.

49. Ingenbleek Y, Bernstein LH. Plasma transthyretin as a biomarker of lean body mass and catabolic states. Adv Nutr. 2015;6:572-80. 